\title{
INFRARED LASER PHOTOCHEMISTRY OF TRANS-1, 2-DICHLOROETHYLENE. EVIDENCE FOR A Cl ATOM CHAIN REACTION
}

\author{
JOSEPH R. GUCKERT and ROBERT W. CARR \\ Department of Chemical Engineering and Materials Science, University of \\ Minnesota, Minneapolis, MN, 55455
}

(Received 1 May, 1989; in final form 10 September, 1989)

\begin{abstract}
The TEA- $\mathrm{CO}_{2}$ laser induced reaction of trans-1,2-dichloroethylene (TDCE) was investigated at 925 $\mathrm{cm}^{-1}$. The laser radiation was focused to yield beam waist fluences of approximately $125 \mathrm{~J} \mathrm{~cm}^{-2}$. The major reaction product was $c i s-1,2$-dichloroethylene $(C D C E)$, with a few per cent of chloroacetylene, and minor amounts of acetylene, dichloroacetylene, chloroethylene and an unidentified $\mathrm{C}_{4}$ compound also being formed. The reaction of pure TDCE was studied as a function of number of laser pulses and total pressure ( 0.02 to 5 torr). Some experiments were also done with added ethane $(20 \%)$ and propane $(2 \%)$. Evidence was obtained that the formation of the cis isomer occurs via two mechanisms, (1) a unimolecular isomerization, and (2) a $\mathrm{Cl}$ atom chain reaction. The results are consistent with laser induced decomposition of TDCE occurring through the three lowest energy channels: unimolecular structural isomerization $(57.4 \mathrm{kcal} / \mathrm{mol})$; molecular $\mathrm{HCl}$ elimination $(69 \mathrm{kcal} / \mathrm{mol})$; and $\mathrm{C}-\mathrm{Cl}$ bond scission $(89 \mathrm{kcal} / \mathrm{mol})$.
\end{abstract}

KEY WORDS: IR multiphoton, decompositions, trans-1,2-dichloroethylene.

\section{INTRODUCTION}

We have been interested in experimental characterization of reaction temperature in laser powered pyrolysis. An approach to this problem that appears promising is the measurement of the temperature dependent equilibrium composition in isomerization reactions. We selected trans-1,2-dichloroethylene (TDCE) as a candidate for such a study since investigations of its multiple photon photochemistry reported the dominant reaction to be isomerization to cis-1,2-dichloroethylene $(C D C E)$, with only minor amounts of fragmentation occurring. ${ }^{1-4}$ Furthermore, the equilibrium cis to trans ratio is calculated to decrease from 2.46 to 1.07 as temperature increases from $300 \mathrm{~K}$ to $1500 \mathrm{~K}$ using statistically derived thermodynamic functions. ${ }^{5}$ During the course of this work we discovered that the isomerization occurs by two mechanisms, a unimolecular transformation, and a $\mathrm{Cl}$ atom catalyzed chain reaction.

\section{EXPERIMENTAL}

Samples of $T D C E$ and $C D C E$ were obtained from the Aldrich Chemical Company. Their purity was checked by gas chromatography. TDCE contained small amounts 
of $C D C E(1.06 \%), 1,1$-dichloroethylene $(0.37 \%)$ and acetone $(0.59 \%)$. Both samples were degassed and used without further purification.

Cylindrical reaction vessels were constructed from $2.5 \mathrm{~cm}$ diameter Pyrex tubing, with planar $\mathrm{NaCl}$ windows attached by epoxy cement at each end, and a glass-Teflon vacuum valve at the mid-point. Their length was either $29.3 \mathrm{~cm}$ or $12.8 \mathrm{~cm}$. The cells were evacuated to $10^{-5}$ torr before each experiment. Pressures were measured with either an ionization gauge or a capacitance manometer.

A Lumonics 102 TEA CO $\mathrm{CO}_{2}$ laser, tuned to the $\mathrm{P}(40)$ line at $925 \mathrm{~cm}^{-1}$, was used for all photolyses. The laser pulse had a FWHM of $160 \mathrm{~ns}$ as measured with a photon drag detector. The radiation was focused at the center of the $29.3 \mathrm{~cm}$ reactor by a $40 \mathrm{~cm}$ focal length $\mathrm{Ge}$ lens in most experiments. A $1.54 \mathrm{~cm}$ diameter circular aperture, placed before the lens, selected a very nearly uniform radial intensity distribution from the laser beam. The laser pulse energies, reported as fluences $\left(\mathrm{J} / \mathrm{cm}^{2}\right)$, were calculated for a point inside the front window based on the area of the aperture. The actual fluence inside the front window of the reactor was greater than this due to the reduced area of the partially focused beam at that point. The diameter at the beam waist was approximately $1 \mathrm{~mm}$, producing fluences up to $125 \mathrm{~J}-\mathrm{cm}^{-2}$. Laser pulse energy was measured by a Scientech calorimeter and power meter connected to a homebuilt integrator. ${ }^{6}$

Reaction product mixtures were analysed by FID gas chromatography, using a $3 \mathrm{ft}$ Porapak Q column operated at $115^{\circ} \mathrm{C}$. For some analyses the column length was increased to $6 \mathrm{ft}$. For quantitation of the reaction products the response of the FID was assumed proportional to number of carbon atoms. Positive identification of the products was made by GC-MS.

\section{RESULTS}

The infrared spectra of $T D C E$ and $C D C E$ are shown in Figure 1. While $C D C E$ does not have any absorption features between $900-1100 \mathrm{~cm}^{-1}, T D C E$ has a band centered at $898 \mathrm{~cm}^{-1}$ which extends into the $\mathrm{CO}_{2}$ laser frequency range. This band, containing well defined rotational lines, corresponds to an out-of-plane wagging motion of the $\mathrm{CHCl}$ groups. ${ }^{5,7}$

The major product from multiple photon infrared excitation of $T D C E$ at $925 \mathrm{~cm}^{-1}$ is its isomer $C D C E$. Several decomposition products are also formed, the most abundant (up to $12 \%$ ) being chloroacetylene. The other products, acetylene, dichloroacetylene, chloroethylene and an unidentified compound are formed in small amounts (approx. 1\% or less). Evidence suggests that the unidentified compound was a $\mathrm{C}_{4}$ species, probably diacetylene. The acetone impurity decreased upon irradiation, but the influence of this reaction was small because of its trace amount. The quantity of the other impurity, 1,1-dichloroethylene, did not change significantly during photolysis.

The per cent conversions of $T D C E$ as a function of the number of laser pulses at 5 torr and at 0.05 torr are shown in Figure 2. At each pressure the conversions reach a constant limiting value that is less than $100 \%$. The 5 torr data are nearly at their 


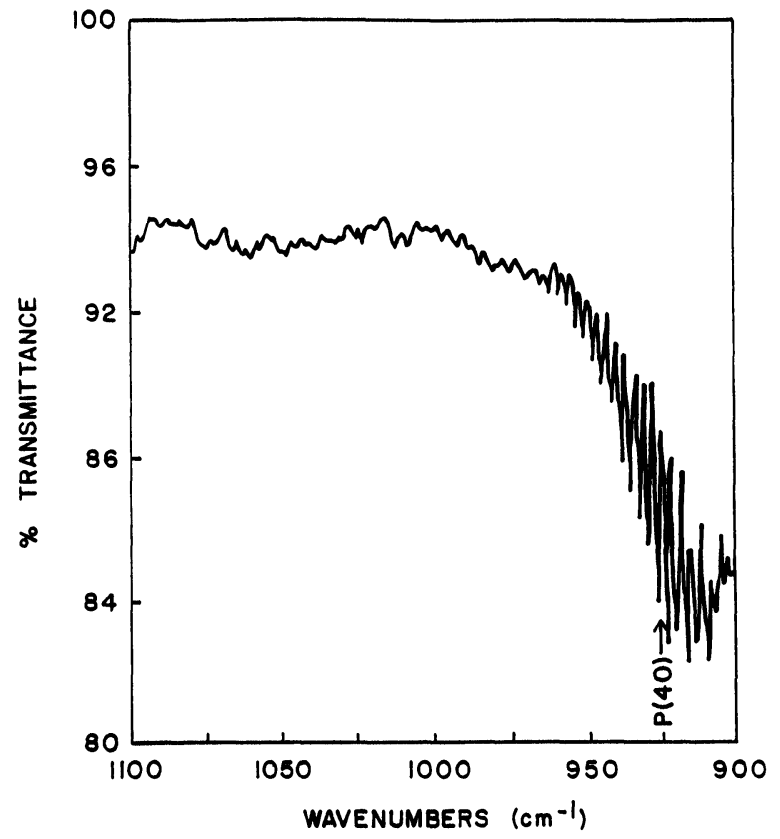

(a)

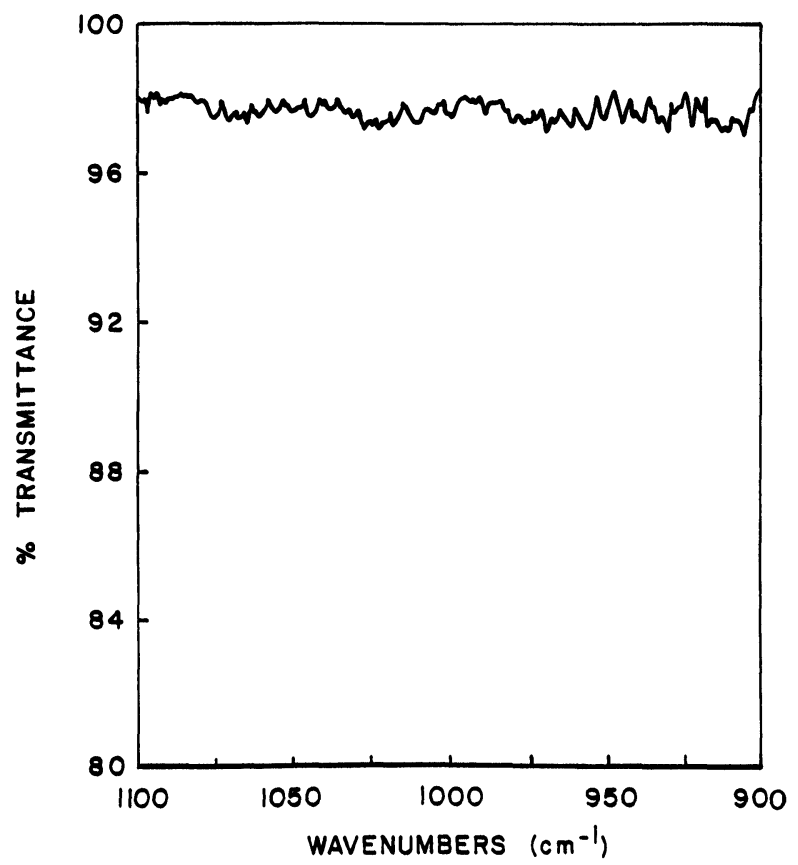

(b)

Figure 1 (a) FTIR spectrum of trans-1,2-dichloroethylene: 3 torr, $10 \mathrm{~cm}$ cell. (b) FTIR spectrum of cis-1,2-dichloroethylene: 3 torr, $10 \mathrm{~cm}$ cell. 


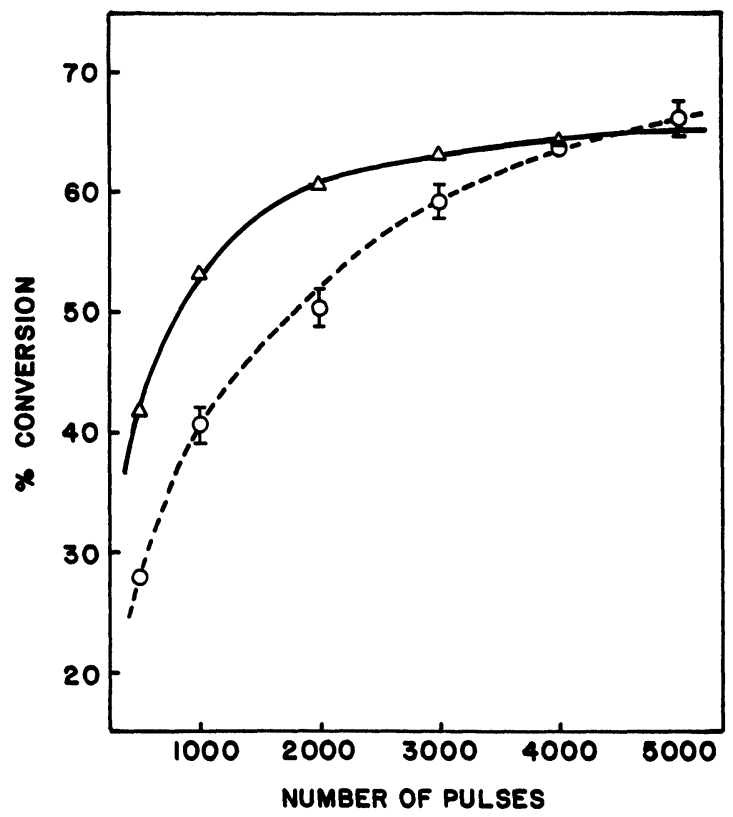

Figure 2 Conversion of trans-1,2-dichloroethylene $v s$ number of laser pulses: $0.5 \mathrm{~J} / \mathrm{cm}^{2},--0.5$ torr, -5 torr.

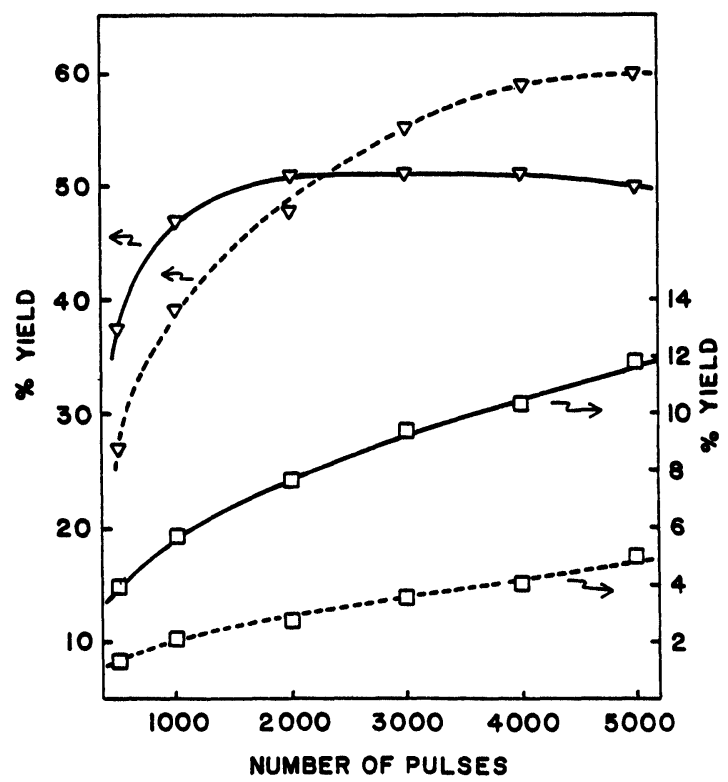

Figure 3 Yield of cis-dichloroethylene, $\nabla$, and chloroacetylene, $\square$, vs number of pulses:.--0.5 torr, -5 torr. 
limiting value by 3000 to 4000 pulses, and the 0.05 torr conversions reached $68 \%$ after 8000 pulses, compared with $66 \%$ after 5000 pulses. Also, the limiting 5 torr conversion is slightly less than the limiting 0.05 torr conversion.

The yields of $C D C E$ and chloroacetylene from the 0.05 and 5 torr experiments are plotted $v s$ number of laser pulses in Figure 3 . The 5 torr yield of chloroacetylene is significantly larger than the 0.05 torr yield over the entire range of pulses investigated, while for $C D C E$ the yields cross between 2000 and 3000 pulses. The 5 torr yield of $C D C E$ decreases slightly after about 2000 to 3000 pulses, while chloroacetylene continues to increase. On the other hand, the 0.05 torr yields of $C D C E$ and chloroacetylene remain constant, within experimental error, above 5000 torr since the 8000 pulse yields of these species are $61.5 \%$ and $5.6 \%$, respectively.

Spots the size of the laser beam appeared on the reaction vessel windows in the 5 torr experiments if the reactor was not evacuated for a sufficient period of time. When spots appeared, the windows were replaced. Several experiments were conducted to determine if heterogeneous reactions were occurring on the windows, as reported in a previous study of the MPD of $T D C E .{ }^{3}$ The short reaction vessel was placed between the laser output coupler and the beam waist so that the fluence incident on its rear window was comparable to the influence inside the front windows of the longer cell used for routine experiments (about $4-5 \mathrm{~J} / \mathrm{cm}^{2}$ ). In several experiments at 5 torr, including an 8500 pulse run, neither reaction products nor window spots were detected. However, at 0.05 torr, $C D C E$ was produced at $1 \%$ per 1000 pulses. We conclude that the contribution of surface reactions to the observed volatile products is negligible under our conditions.

Additional experiments were performed with pure $C D C E$. Although it does not have a readily discernible fundamental absorption band within the $\mathrm{CO}_{2}$ laser frequency range, $C D C E$ has been reported to give small yields of $T D C E$ upon laser irradiation at $935 \mathrm{~cm}^{-1} .{ }^{1}$ In the present $925 \mathrm{~cm}^{-1}$ experiments, the yield of $T D C E$ after 3000 pulses was $1 \%$ at 5 torr and $3.5 \%$ at 0.05 torr. Thus, MPD of $C D C E$ is minor compared to that of TDCE.

The effect of pressure was investigated by photolyzing TDCE over the range 0.02 torr to 5 torr. All of these experiments were conducted at $0.5 \mathrm{~J} / \mathrm{cm}^{2}$ and 5000 pulses since both the conversion and the yield of $C D C E$ approached limiting values at these conditions. The results are in Table 1 . The data, reported as area \%, does not contain the acetone and 1,1-dichloroethylene impurities in TDCE since these were only accurately measurable at sample pressures above 3 torr due to longer GC retention times than the other trace species reported, $\mathrm{C}_{2} \mathrm{H}_{2}$ and $\mathrm{C}_{2} \mathrm{H}_{5} \mathrm{Cl}$, and even then would make negligible changes in reported percentages. The area per cent of $C D C E$ and chloroacetylene in 5000 pulse experiments are plotted $v s$ pressure in Figures 4 and 5.

Some experiments were done with mixtures of $2 \%$ propane in TDCE. The small amount of propane should have very little effect on the excitation of TDCE. Table 2 shows that the yield of $C D C E$ is reduced by about one third over a wide pressure range with the addition of propane. Furthermore, analysis of the irradiated mixture on the longer GC column revealed that propane underwent reaction. At 0.05 torr about $50 \%$ of the propane is consumed, which increases to about $75 \%$ at 5 torr. 
Table 1 Reaction mixture composition from TDCE irradiation. 5000 pulses; $0.5 \mathrm{~J} / \mathrm{cm}^{2}$

\begin{tabular}{lcccccccc}
\hline & \multicolumn{8}{c}{ area \% } \\
\cline { 2 - 9 }$P$ (torr) & $\mathrm{C}_{2} \mathrm{H}_{2}$ & $\mathrm{C}_{2} \mathrm{HCl}$ & $\mathrm{C}_{2} \mathrm{H}_{3} \mathrm{Cl}$ & $\mathrm{C}_{4}$ & $\mathrm{C}_{2} \mathrm{Cl}_{2}$ & $T D C E$ & $C D C E$ & $\begin{array}{c}\text { CDCEl } \\
\text { TDCE }\end{array}$ \\
\hline 0.2 & 0.35 & 6.27 & - & 1.44 & - & 56.3 & 35.1 & 0.62 \\
0.5 & 0.21 & 5.01 & - & 1.22 & - & 33.5 & 59.8 & 1.78 \\
0.1 & 0.24 & 3.53 & 0.32 & 0.93 & - & 28.2 & 66.9 & 2.37 \\
0.2 & 0.21 & 3.55 & 0.25 & 0.51 & - & 28.5 & 67.2 & 2.36 \\
$\mathbf{0 . 4}$ & 0.51 & 4.47 & 0.40 & 0.69 & - & 29.5 & 64.4 & 2.18 \\
0.8 & 0.49 & 5.21 & 0.37 & 0.87 & - & 31.4 & 61.7 & 1.97 \\
1.6 & 0.64 & 6.12 & 0.33 & 1.00 & - & 33.1 & 58.8 & 1.78 \\
$\mathbf{3 . 2}$ & 1.63 & 7.93 & 0.43 & 1.29 & - & 33.3 & 55.2 & 1.66 \\
5.0 & 1.58 & 11.8 & 0.27 & 1.57 & 0.46 & 34.3 & 49.9 & 1.46 \\
\hline
\end{tabular}

Propylene is formed in these experiments, although its amount cannot compensate for the loss of propane. Direct photodecomposition of propane was shown not to occur by irradiation of pure propane.

Similar results were obtained from the irradiation of an $80 \% T D C E / 20 \%$ ethane mixture. The results in Table 3 show that after correcting for the initial ethane concentration the yield of $C D C E$ at both 0.05 and 5 torr is reduced by more than a factor of two with ethane present. While ethane at this pressure may quench hot $T D C E$ or other intermediates leading to $C D C E$, it is unlikely that this alone can account for the loss of $C D C E$ since quenching should be virtually absent at 0.05 torr, and large reductions in $C D C E$ yield are observed at this pressure. Also, the

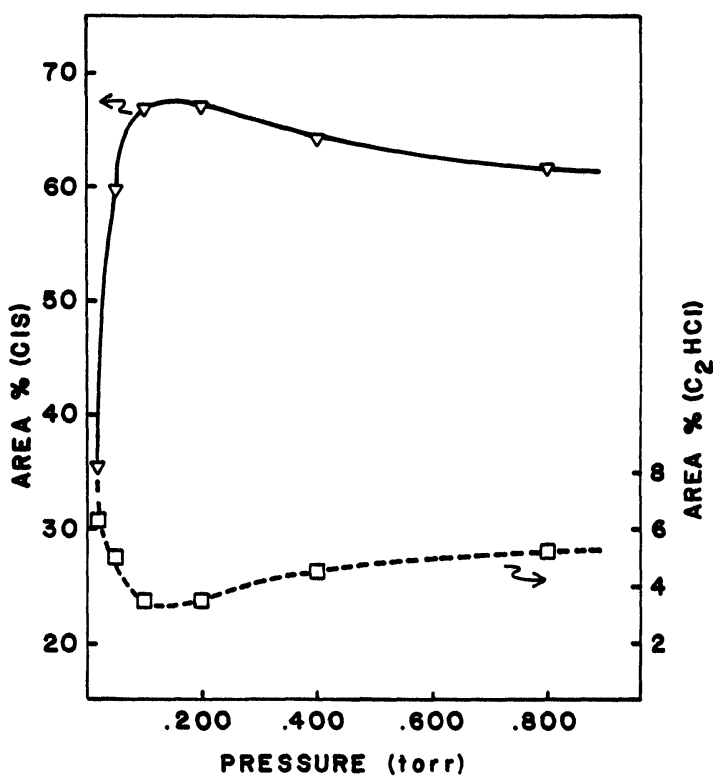

Figure 4 Area \% of $c$ is-dichloroethylene, $\nabla$, and chloroacetylene, $\square$, vs initial pressure: $0.5 \mathrm{~J} / \mathrm{cm}^{2}, 5000$ pulses. 


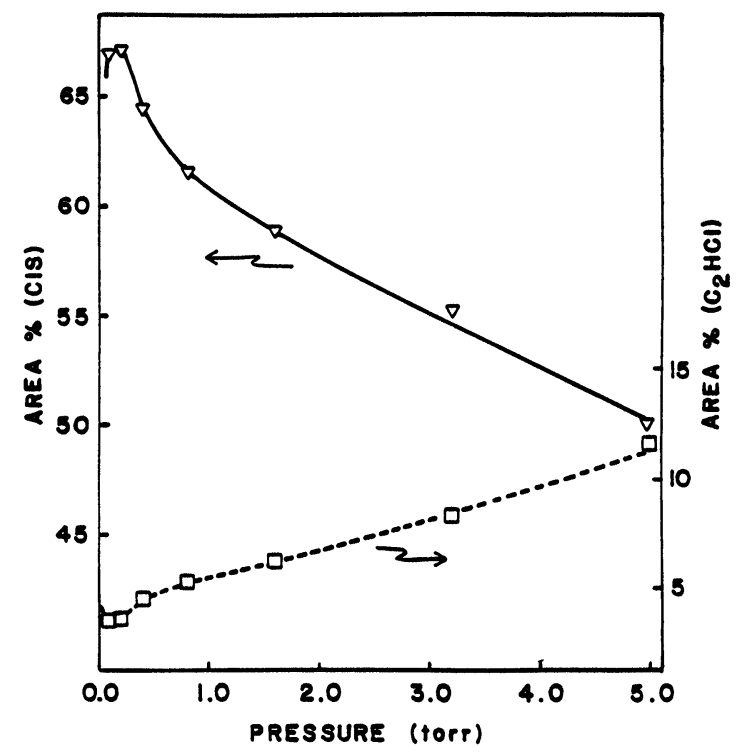

Figure 5 Area \% of cis-dichloroethylene, $\nabla$, and chloroacetylene, $\square, v s$ initial pressure: $0.5 \mathrm{~J} / \mathrm{cm}^{2}, 5000$ pulses.

Table 2 Comparison of product mixture from $T D C E$ with $98 \% T D C E / 2 \%$ propane 1000 pulses; $0.5 \mathrm{~J} / \mathrm{cm}^{2}$

\begin{tabular}{lcccccccc}
\hline & \multicolumn{8}{c}{ area \% } \\
\cline { 2 - 10 }$P$ (torr) & $C_{2} H_{2}$ & $C_{3} H_{6}$ & $C_{2} H C l$ & $C_{2} H_{3} C l$ & $C_{4}$ & $T D C E$ & $C D C E$ & TDCE \\
\hline & & \multicolumn{7}{c}{ pure TDCE } \\
0.05 & - & - & 2.07 & - & - & 58.7 & 39.1 & 0.67 \\
0.2 & - & - & 1.32 & - & - & 46.9 & 51.8 & 1.10 \\
5.0 & 0.51 & - & 5.71 & 0.20 & 0.51 & 46.2 & 46.7 & 1.01 \\
& & & $98 \%$ & $T D C E / 2 \%$ & $C_{3} \mathrm{H}_{8}$ & & & \\
0.05 & 0.23 & - & 1.73 & - & - & 68.1 & 27.5 & 0.40 \\
0.20 & 0.23 & 0.20 & 1.74 & 0.14 & - & 62.1 & 34.3 & 0.55 \\
5.0 & 2.21 & 0.31 & 7.89 & 0.67 & 1.10 & 56.7 & 30.1 & 0.53 \\
\hline
\end{tabular}

Table 3 Comparison of TDCE with $80 \%$ TDCE/20\% $\mathrm{C}_{2} \mathrm{H}_{6}$ Irradiations. (3000 pulses; $0.5 \mathrm{~J} / \mathrm{cm}^{2}$ )

\begin{tabular}{|c|c|c|c|c|c|c|c|}
\hline \multirow[b]{2}{*}{$P($ torr $)$} & \multicolumn{7}{|c|}{ area $\%$} \\
\hline & $\mathrm{C}_{2} \mathrm{HCl}$ & $\mathrm{C}_{2} \mathrm{H}_{3} \mathrm{Cl}$ & $\mathrm{C}_{4}$ & $\mathrm{C}_{2} \mathrm{Cl}_{2}$ & $T D C E$ & $C D C E$ & $C D C E / T D C E$ \\
\hline \multicolumn{8}{|c|}{ pure $T D C E$} \\
\hline 0.5 & 3.53 & - & 0.71 & - & 40.4 & 55.2 & 1.37 \\
\hline 5.0 & 9.39 & 0.26 & 1.25 & 0.43 & 36.3 & 51.1 & 1.41 \\
\hline \multicolumn{8}{|c|}{$80 \%$ TDCE $/ 20 \% \mathrm{C}_{2} \mathrm{H}_{6}$} \\
\hline 0.5 & 4.86 & - & 1.95 & - & 56.9 & 19.4 & 0.34 \\
\hline 5.0 & 9.28 & 0.93 & 3.18 & - & 45.4 & 21.7 & 0.48 \\
\hline
\end{tabular}


chloroacetylene yields are relatively unaffected by ethane at either pressure. Unfortunately, changes in the acetylene yield could not be determined due to incomplete GC separation.

In another experiment the fluence was attenuated with $\mathrm{CaF}_{2}$ flats. The beam was focused in the center of the short cell, producing a fluence of approximately $40 \mathrm{~J} / \mathrm{cm}^{2}$, $68 \%$ lower than in the preceding experiments, at the beam waist. Yet the addition of $2 \%$ propane resulted in a $70 \%$ reduction of the $C D C E$ yield ( 5 torr, $2 \times 10^{3}$ pulses), indicating that the scavengeable intermediate is still present at the lower fluence.

\section{DISCUSSION}

Table 4 lists possible reaction channels of TDCE, and an estimate of the energy requirement for the lowest four. No estimate of the energy for $\mathrm{Cl}_{2}$ and $\mathrm{H}_{2}$ elimination was made. The lowest energy channel is the unimolecular isomerization, which may be represented by reaction scheme 1 .

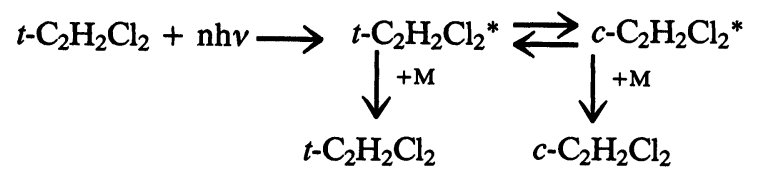

In scheme 1 , asterisk represents a highly vibrationally excited species.

Since infrared multiple photon processes are frequently dominated by the lowest energy channel, scheme (1) is expected to occur. However, the formation of decomposition products suggest that some of the higher energy channels in Table 4 may also be accessed at the experimental conditions of this work.

Table 4 Possible reaction channels of TDCE

\begin{tabular}{|c|c|c|}
\hline & $E_{\mathrm{a}}(\mathrm{kcal} / \mathrm{mol})$ & Ref \\
\hline $\begin{array}{l}\text { TDCE } \rightarrow \mathrm{CDCE} \\
\text { TDCE } \rightarrow \mathrm{C}_{2} \mathrm{HCl}+\mathrm{HCl} \\
\mathrm{TDCE} \rightarrow \mathrm{C}_{2} \mathrm{H}_{2} \mathrm{Cl}+\mathrm{Cl} \\
\mathrm{TDCE} \rightarrow \mathrm{C}_{2} \mathrm{HCl}_{2}+\mathrm{H} \\
\mathrm{TDCE} \rightarrow \mathrm{C}_{2} \mathrm{H}_{2}+\mathrm{Cl}_{2} \\
\mathrm{TDCE} \rightarrow \mathrm{C}_{2} \mathrm{Cl}_{2}+\mathrm{H}_{2}\end{array}$ & $\begin{array}{l}57.4 \\
69 \\
89 \\
108 \\
- \\
-\end{array}$ & $\begin{array}{c}13,14 \\
15 \\
16 \\
16\end{array}$ \\
\hline
\end{tabular}

An indication that reaction (1) by itself cannot account for the isomerization comes from the data in Figure 4, which show that $C D C E$ and chloroacetylene, which together account for more than about $95 \%$ of the products, make up at the most about $70 \%$ of the reaction mixture. Furthermore, the conversions in Figure 2 show that the reaction cannot be driven to completion, even at 0.05 torr. This is not the expected result if the isomerization occurs by unimolecular transformation of laser pumped TDCE since $C D C E$ does not photolyze appreciably, and in a unimolecular isomerization $T D C E$ should be able to be essentially completely converted at pressures low enough that collisions are not significant during the laser pulse. At 0.05 torr the collision interval is about $1.4 \mu \mathrm{sec}$. 
The results from the experiments with added propane and ethane provide additional evidence that cis-trans isomerization occurs at least in part by another reaction path. The reduction of the $C D C E$ yield, the consumption of propane and the production of propylene strongly suggest that propane acts to suppress a portion of the overall reaction involving thermal reactions of a reactive intermediate that causes isomerization of $T D C E$. The species responsible is most probably atomic $\mathrm{Cl}$, which may originate directly by $\mathrm{C}-\mathrm{Cl}$ bond scission.

If laser excited TDCE undergoes $\mathrm{C}-\mathrm{Cl}$ bond cleavage, the $\mathrm{Cl}$ atoms can promote reversible cis-trans isomerization, providing an explanation for the inability to drive the reaction to completion. Steel ${ }^{8}$ suggest a $\mathrm{Cl}$ atom chain reaction in the thermal isomerization of TDCE, while Ayscough et al. ${ }^{9}$ and Knox and Riddick ${ }^{10}$ found evidence from photochlorination studies that isomerization proceeds via a chemically activated $\mathrm{Cl}$ atom adduct. Furthermore, $\mathrm{C}-\mathrm{Cl}$ bond scission has been observed in MPD of several halocarbons, including trichloreothylene. ${ }^{11}$ The following reactions should then be considered.

$$
\mathrm{Cl}+t-\mathrm{C}_{2} \mathrm{H}_{2} \mathrm{Cl}_{2} \underset{k-\mathrm{t}}{\stackrel{k_{3}}{\rightleftarrows}} \mathrm{C}_{2} \mathrm{H}_{2} \mathrm{Cl}_{3} * \stackrel{k_{-\mathrm{c}}}{\underset{k_{\mathrm{c}}}{\rightleftarrows}} c-\mathrm{C}_{2} \mathrm{H}_{2} \mathrm{Cl}_{2}+\mathrm{Cl}
$$

The addition of $\mathrm{Cl}$ occurs readily. The $298 \mathrm{~K}$ rate constants are reported to be $6.64 \times 10^{-11} \mathrm{~cm}^{3}$ molecule ${ }^{-1} \mathrm{~s}^{-1}(\mathrm{Cl}+T D C E)$ and $9.96 \times 10^{-11} \mathrm{~cm}^{3}$ molecule $\mathrm{s}^{-1}(\mathrm{Cl}+C D C E) \cdot{ }^{17}$ Isomerization will occur at the pressures of this work since the chemically activated trichloroethyl radical is only $50 \%$ collisionally stabilized at 150 torr, ${ }^{10}$ and furthermore, Wai and Rowland have reported the lifetime for rotation about the $\mathrm{C}-\mathrm{C}$ bond to be $<10^{-10} \mathrm{~s} \cdot{ }^{18}$ Finally, reactions 3 and 4 are competitive with addition of $\mathrm{Cl}$ to $T D C E$ and $C D C E$ even at room temperature, where their rate constants have the values $5.7 \times 10^{-11} \mathrm{~cm}^{3}$ molecule ${ }^{-1} \mathrm{~s}^{-1}$ and $1.6 \times 10^{-10} \mathrm{~cm}^{3}$ molecule ${ }^{-1} \mathrm{~s}^{-1}$, respectively. ${ }^{19}$

$$
\begin{aligned}
& \mathrm{Cl}+\mathrm{C}_{2} \mathrm{H}_{6}=\mathrm{HCl}+\mathrm{C}_{2} \mathrm{H}_{5} \\
& \mathrm{Cl}+\mathrm{C}_{3} \mathrm{H}_{8}=\mathrm{HCl}+\mathrm{C}_{3} \mathrm{H}_{7}
\end{aligned}
$$

It is also possible to envision $\mathrm{H}$ atom catalyzed isomerization. Production of $\mathrm{H}$ atoms by the cleavage of $\mathrm{C}-\mathrm{H}$ bonds during MPD may occur, but is less likely than $\mathrm{C}-\mathrm{Cl}$ rupture due to the higher energy required. Furthermore, attack of either $C D C E$ of $T D C E$ by addition of $\mathrm{H}$ to the double bond would be followed by elimination of $\mathrm{Cl}$ in preference to $\mathrm{H}$, leading to the formation of $\mathrm{C}_{2} \mathrm{H}_{3} \mathrm{Cl}$. Small amounts of this substance are formed, and provide evidence that $\mathrm{H}$ atoms may be present. However, the yield of $\mathrm{C}_{2} \mathrm{H}_{3} \mathrm{Cl}$ is not reduced, but rather increased when ethane or propane are added. Thus any $\mathrm{H}$ atoms present are not scavenged by these species, consistent with the higher activation energy for abstraction of $\mathrm{H}$ from the $\mathrm{C}-\mathrm{H}$ bonds by $\mathrm{H}$ atoms $(7-9 \mathrm{kcal} / \mathrm{mol}$ ) than by $\mathrm{Cl}$ atoms (approx. $0.1 \mathrm{kcal} / \mathrm{mol}$ ). The reduction of $C D C E$ yields upon addition of ethane or propane can be best explained if isomerization occurs via the $\mathrm{Cl}$ atom chain of scheme 2 , and $\mathrm{Cl}$ atoms are scavenged by ethane and propane.

In addition to $\mathrm{C}-\mathrm{Cl}$ photodissociation, $\mathrm{Cl}$ atoms may be formed by $\mathrm{HCl}$ elimination from hot TDCE followed by secondary photolysis of the product $\mathrm{C}_{2} \mathrm{HCl} . \mathrm{HCl}$ 
elimination is energetically favoured over $\mathrm{C}-\mathrm{Cl}$ cleavage. Elimination of $\mathrm{HCl}$ has been reported in the MPD of chloroethylene ${ }^{4}$ and trichloroethylene. ${ }^{12}$

The presence of $\mathrm{Cl}$ atoms offers an explanation for the inability to drive the multiphoton reaction of $T D C E$ to completion at low pressures. The finite cis/trans ratios could be due to competition between the depletion of TDCE by reaction scheme 1 and its regeneration by $\mathrm{Cl}$ catalyzed isomerization. Also, the amount of $\mathrm{Cl}$ is probably proportional to $\mathrm{C}_{2} \mathrm{HCl}$ which is either produced concurrently with $\mathrm{Cl}$, or is a precursor of $\mathrm{Cl}$ by secondary photolysis. Thus, a decrease in the $\mathrm{C}_{2} \mathrm{HCl}$ yield should be accompanied by an increase in the $C D C E$ yield because of a reduction in the radical catalyzed isomerization. This trend is observed in Figure 4 at pressures less than 0.1 torr, where thermal effects should be absent.

Above 0.2 torr the $C D C E / T D C E$ ratio decreases with increasing pressure. Since the isomerization is exothermic, this trend would be predicted if the system were thermalized by collisional redistribution of deposited vibrational energy. The ratio $C D C E / T D C E=1.46$ at 5 torr corresponds to a temperature of $610 \mathrm{~K}$ if chemical equilbrium is reached. However, at this temperature the value of the overall thermal unimolecular rate constant is $6 \times 10^{-8} \mathrm{sec}^{-1},{ }^{13,14}$ which is much too low to account for the observed isomerization yield since the reaction time is only expected to be a few $\mu$ sec. ${ }^{20}$ If the transient temperature were enough higher to produce thermal reaction rates permitting equilibrium to be approached in this short time, $C D C E /$ $T D C E$ would be smaller than observed. Thus, at 5 torr the system must still not be totally thermalized.

While a thorough investigation of the formation of minor products was not done, observed trends in their yields permit some tentative, qualitative conclusions to be drawn.

The presence of $\mathrm{C}_{2} \mathrm{HCl}$ is most easily explained by elimination of $\mathrm{HCl}$ from vibrationally excited $T D C E$ and $C D C E$. It may also arise by $\mathrm{H}$ elimination from $\mathrm{C}_{2} \mathrm{H}_{2} \mathrm{Cl}$ radicals, either thermally or via secondary photolysis. A possible route to $\mathrm{C}_{2} \mathrm{HCl}$ consisting of $\mathrm{H}$ abstraction from either TDCE or $C D C E$ by $\mathrm{Cl}$, followed by $\mathrm{Cl}$ elimination from the $\mathrm{C}_{2} \mathrm{HCl}$ is unaffected by the $\mathrm{Cl}$ atom scavengers $\mathrm{C}_{2} \mathrm{H}_{6}$ and $\mathrm{C}_{3} \mathrm{H}_{8}$. The initial decrease of $\mathrm{C}_{2} \mathrm{HCl}$ with increasing pressure may be explained if collisional deactivation is responsible for a decrease in the relative importance of the higher energy $\mathrm{HCl}$ elimination channel relative to the cis-trans isomerization channel at pressures below 0.1 torr. Around 0.1 torr collisions between two TDCE* molecules become possible, since the lengths of the mean free path $(\mathrm{ca} .0 .2 \mathrm{~mm})$ and the radius of the beam at the focal point (ca. $0.5 \mathrm{~mm}$ ) are comparable. If these collisions promote further up-pumping of one of the colliders, they will enable the reaction to proceed through the higher energy reaction channel, providing an explanation for the increase in $\mathrm{C}_{2} \mathrm{HCl}$ yield with increasing pressure.

While acetylene formation may be explained by elimination of $\mathrm{Cl}$ from $\mathrm{C}_{2} \mathrm{H}_{2} \mathrm{Cl}$ radicals and possibly also by $\mathrm{Cl}_{2}$ elimination from hot $T D C E$ and $C D C E$, the increase of acetylene yield in the presence of the $\mathrm{Cl}$ atom scavengers provides an argument that a sequence consisting of $\mathrm{H}$ abstraction from $T D C E$ or $C D C E$ by atomic chlorine, followed by $\mathrm{Cl}$ elimination, may occur. Also, the increase of $\mathrm{C}_{2} \mathrm{H}_{3} \mathrm{Cl}$ in the presence of propane and ethane suggests that this species may be 
formed via $\mathrm{H}$ abstraction by $\mathrm{C}_{2} \mathrm{H}_{2} \mathrm{Cl}$ radicals. There is insufficient information on $\mathrm{C}_{2} \mathrm{Cl}_{2}$ except to say that it may arise from $\mathrm{H}_{2}$ elimination from either TDCE or CDCE.

An estimate of the importance of reaction channel three, $\mathrm{C}-\mathrm{Cl}$ dissociation, can be made by estimating chain lengths for the $\mathrm{Cl}$ atom catalyzed isomerization. If chain termination in pure $T D C E$ is assumed to occur by $\mathrm{H}$ atom transfer from $T D C E$ to $\mathrm{Cl}$, reaction 5;

$$
\mathrm{Cl}+\mathrm{C}_{2} \mathrm{H}_{2} \mathrm{Cl}_{2}=\mathrm{HCl}+\mathrm{C}_{2} \mathrm{HCl}_{2}
$$

the chain length is given by $k_{t} / \mathrm{k}_{5}$. Data reported in Cillien $e t$ al. ${ }^{21}$ can be used to estimate $k_{5}=6 \times 10^{-13} \mathrm{~cm}^{3}$ molecule ${ }^{-1} \mathrm{~s}^{-1}$ at $298 \mathrm{~K}$, from which the chain length is approximately 100 . If the dominant termination step in the presence of ethane or propane is reaction 3 or 4 , respectively, then the chain lengths are about 6 or 18 at 298K. Applying these estimates of chain length to the low pressure data and assuming that $T D C E$ is formed by only the two routes of schemes 1 and 2 it can be concluded that $\mathrm{C}-\mathrm{Cl}$ bond scission is only $1 \%$ relative to laser selective unimolecular isomerization. Also, if $\mathrm{C}_{2} \mathrm{HCl}$ is assumed to arise solely by $\mathrm{HCl}$ elimination from $T D C E$ at low pressures, then its yields can be used to estimate that the $\mathrm{HCl}$ elimination channel is about $10-12 \%$ relative to laser selective unimolecular isomerization.

\section{Acknowledgement}

Support of the National Science Foundation through Grant No. CPE-8023180 is gratefully acknowledged.

\section{References}

1. R. V. Ambartzumian, N. V. Chekalin, V. S. Doljikov, V. S. Letokhov and V. N. Lokham, J. Photochem 6, 55 (1976/77).

2. K. Nagai and M. Katayama, Chem. Phys. Lett. 51, 329 (1977).

3. Z. Karny and R. N. Zare, Chem. Phys. 23, 321 (1977).

4. C. Reiser, F. M. Lussier, C. C. Jensen and J. I. Steinfeld, J. Am. Chem. Soc. 101, 350 (1979).

5. K. S. Pitzer and J. L. Hollenberg, J. Am. Chem. Soc. 76, 1493 (1954).

6. J. O. Shoemaker and R. W. Carr, Rev. Sci. Instrum. 53, 1086 (1982).

7. H. J. Bernstein and D. A. Ramsay, J. Chem. Phys. 17, 556 (1949).

8. C. Steel, J. Phys. Chem. 64, 1588 (1960).

9. P. B. Ayscough, A. J. Cocker and F. S. Dainton, Trans. Faraday Soc. 58, 284 (1962).

10. J. H. Knox and J. Riddick, Trans Faraday Soc. 62, 1190 (1966).

11. Aa. S. Sudbo, P. A. Schulz, E. R. Grant, Y. R. Shen and Y. T. Lee, J. Chem. Phys. 68, 1306 (1978).

12. J. F. Caballero and C. Wittig, J. Chem. Phys. 78, 7169 (1983).

13. L. D. Hawton and G. P. Semeluk, Can. J. Chem. 44, 2143 (1966).

14. P. M. Jeffers, J. Phys. Chem. 76, 2829 (1972).

15. Estimated from the $\mathrm{HCl}$ elimination from vinyl chloride. F. Zabel, Int. J. Chem. Kinet, 9, 651 (1977).

16. S. W. Benson, Thermochemical Kinetics: Methods for the Estimation of Thermochemical Data and Rate Parameters, Wiley, N.Y. 1968.

17. J. Knox and K. C. Waugh, Trans. Faraday Soc. 65, 1585 (1970).

18. C. M. Wai and F. S. Rowland, J. Am. Chem. Soc. 91, 1053 (1969).

19. NASA Reference Publication 1208, Present state of Knowledge of the Upper Atmosphere 1988: An Assessment Report.

20. J. R. Guckert and R. W. Carr, J. Phys. Chem. 90, 4286 (1986).

21. C. Cillien, P. Goldfinger, G. Huybrechts and G. Martins, Trans. Faraday Soc. 63, 1631 (1967). 